\title{
GENERAL ETHICS
}

\section{The case for physician assisted suicide: not (yet) proven}

\section{B Steinbock}

J Med Ethics 2005;31:235-241. doi: 10.1136/jme.2003.005801

The legalisation of physician assisted suicide (PAS) in Oregon and physician assisted death (PAD) in the Netherlands has revitalised the debate over whether and under what conditions individuals should be able to determine the time and manner of their deaths, and whether they should be able to enlist the help of physicians in doing so. Although the change in the law is both dramatic and recent, the basic arguments for and against have not really changed since the issue was debated by Glanville Williams and Yale Kamisar nearly 50 years ago. In this paper, the author argues in favour of Kamisar's consequentialist framework. Any change in law and social policy should not be based solely on individual cases, heart wrenching though these may be. Instead, we need to assess the need for PAS, and weigh this against the risks of mistake and abuse.

\footnotetext{
Correspondence to: Professor B Steinbock Department of Philosophy, University at Albany, Albany, NY 12222, USA; steinbock@albany.edu
}

Received 16 July 2003 Accepted for publication 29 January 2004
T (PAS) in Oregon $^{1}$ and physician assisted death $(\mathrm{PAD})$ in the Netherlands has revitalised the debate over whether and under what conditions individuals should be able to determine the time and manner of their deaths, and whether they should be able to enlist the help of physicians in doing so. Although the change in the law is both dramatic and recent, the basic arguments for and against have not really changed since the issue was debated by Glanville Williams ${ }^{2}$ and Yale Kamisar ${ }^{3}$ nearly 50 years ago. Kamisar argued that the real objections to active voluntary euthanasia were not religious, as Williams assumed, but consequentialist. In this paper, I argue in favour of Kamisar's consequentialist framework. The decision to make a sea change in law and social policy should not be based solely on individual cases, heart wrenching though these may be. Instead, we need to assess the need for PAS, and weigh this against the risks of mistake and abuse. Kamisar was convinced (and remains convinced to this day) that it was impossible to draft a statute that could adequately protect vulnerable individuals without being hopelessly cumbersome. ${ }^{4}$ My claim is more modest: it has not yet been demonstrated that the need for a change in the law outweighs the risks such a change would pose. ${ }^{5}$ Moreover, recent problematic cases in Oregon highlight the difficulties in determining the criteria for, and appropriate limitations of, PAS. Let us begin by reviewing the case for legalising PAS. he legalisation of physician assisted suicide

\section{ETHICAL ARGUMENTS IN FAVOUR OF PAS}

The support for PAS comes from two independent, though related, arguments: the argument from suffering and the argument from autonomy.

\section{Suffering}

The argument from suffering asserts that it is cruel to force a dying patient whose pain cannot be controlled with medication to continue living. It is undeniable that many terminally ill patients die in terrible pain. The well known SUPPORT study found that $50 \%$ of conscious patients who died in the hospital experienced moderate to severe pain in the last three days of life. ${ }^{6}$ Dying is bad enough; why should a person have to die in pain? We do not allow dying animals to suffer; we put them out of their misery. Why not do the same for people?

Oregon restricts PAS to competent individuals who have requested it. Yet as many have noted, if the justification for PAS is suffering, why restrict it to competent individuals? Suffering is not limited to individuals who are competent to request death: infants, people with developmental disabilities, and the elderly senile can also experience agonising and irremediable pain. Nor does the argument from suffering apply only to patients who are terminally ill. Indeed, if it is cruel to force someone to go on living who will die shortly anyway, it would seem to be even more cruel to force someone to endure suffering for a longer period.

\section{Autonomy}

Although suffering is a prominent justification given for legalising PAS, it is not only or even primarily physical pain that leads patients to request it. According to the Fifth Annual Report on Oregon's Death with Dignity Act: “... patient requests for lethal medications stemmed from multiple concerns related to autonomy and control at the end of life. The three most commonly mentioned end-of-life concerns during 2002 were: loss of autonomy, a decreasing ability to participate in activities that made life enjoyable, and losing control of bodily functions." ${ }^{1}$

The view that autonomy related concerns were more prominent than fears of pain among Oregonians requesting PAS was confirmed by a study published in the Journal of Palliative Medicine in June 2003. "Being in control and not dependent on other people is the most important thing for them in their dying days,"

Abbreviations: PAD, physician assisted death; PAS, physician assisted suicide. 
said Dr Linda Ganzini, a psychiatrist at Oregon Health \& Science University who led the study. ${ }^{7}$ This was exemplified by one patient quoted by her doctor as saying: "I want to do it on my terms. I want to choose the place and time. I want my friends to be there. And I don't want to linger and dwindle and rot in front of myself".

If suffering is not the basis for most people's request, then we must ask: does the argument from autonomy justify PAS? This depends on how one understands autonomy. ${ }^{8}$ Autonomy is sometimes conceived as a general right to make one's own decisions and choices, so long as one is not harming or violating the rights of others. (The classic statement of this right is given by John Stuart Mill in On Liberty.) Conceived in this broad way, it could include any number of rights, including viewing pornography, taking drugs, having multiple spouses, and so on. But I do not think that the autonomy based argument for PAS is conceived merely as a function of the broader right to live as one pleases, within harm principle constraints. Rather, the principle underlying the argument from autonomy is that "every competent person has the right to make momentous personal decisions which invoke fundamental religious or philosophical convictions about life's value for himself". ${ }^{\prime}$ Death is seen as among the most significant events of a person's life, "the final act of life's drama" which should "reflect our own convictions, those we have tried to live by, not the convictions of others forced on us in our most vulnerable moment". ${ }^{10}$

However, if autonomy is the basis for a right to PAS, why should this right be limited to those who have a terminal illness? Cannot forcing someone to continue living under conditions he or she finds unbearable also be seen as a contradiction of his life, and an odious form of tyranny? This point was made by an American judge: "The depressed twenty one year old, the romantically-devastated twenty eight year old, the alcoholic forty year old who choose suicide are also expressing their views of existence, meaning, the universe, and life; they are also asserting their personal liberty. If at the heart of the liberty protected by the Fourteenth Amendment is this uncurtailable ability to believe and to act on one's deepest beliefs about life, the right to suicide and the right to assistance in suicide are the prerogative of at least every sane adult. The attempt to restrict such rights to the terminally ill is illusory." ${ }^{11}$

\section{The case of Diane Pretty}

This case was seen by many as a clear demonstration that the law regarding PAS in the United Kingdom needs to be changed. Diane Pretty was terminally ill with motor neurone disease, a progressive fatal condition that causes muscle wastage. In her own words, she wanted to avoid death by choking or suffocation: "I want to have a quick death without suffering, at home surrounded by my family so that I can say good-bye to them". Because she was physically unable to commit suicide herself, she sought assurance that her husband would not face prosecution under the Suicide Act if he helped her to die. Technically, then, this would not have been a case of physician assisted but rather husband assisted suicide. However, a physician would almost certainly have been involved, as presumably her husband did not intend to strangle, stab, shoot, or smother his wife, or use any other non-medical means to end her life. Taking a lethal dose of pills would provide the easiest, quickest, most painless death, but to accomplish this, her husband would have needed the cooperation of a physician either to prescribe the drugs, or if she already had the drugs for pain relief, to instruct him on the correct dosage, since too few or too many pills might not result in her (immediate) death, but rather coma. This makes this essentially a case of PAS, even though it was the husband who would have had to help his wife swallow the pills. To my knowledge, no jurisdiction explicitly permits "relative assisted suicide," for obvious reasons. The risk of abuse would be much greater than in PAD. It is conceivable, though unlikely, that a jurisdiction might decide to give well meaning relatives a guarantee of nonprosecution. $^{4}$

In any event, the Director of Public Prosecutions declined to give such assurance, and so, in the words of Baroness Warnock: “... she struggled on, in increasing pain, and at last developed fatal breathing difficulties, and died in hospital in early May [2002]. Doubtless she received what palliative care was possible, but her pain was intense and her cries heartrending." ${ }^{\prime 2}$

Interestingly, Dr Ryszard Bietzk, head of medical services at the Pasque Hospice, Luton, where Mrs Pretty was cared for, characterised her death as "perfectly normal, natural and peaceful". ${ }^{13}$ However, Dr Bietzk is probably describing the very end of her life, after she was terminally sedated, whereas Baroness Warnock is describing her last weeks. In the words of her husband, "They [the hospice staff] had trouble getting her comfortable and pain-free until Thursday evening, after which she started to slip into a coma-like state and eventually died ... Diane had to go through the one thing she had foreseen and was afraid of - and there was nothing I could do to help."13 This was echoed by Baroness Warnock who wrote: "In Diane Pretty's case, she died in the way she dreaded most, because no one could legally ensure that she died otherwise. She was terminally ill; that is to say she could not be cured, and helping her to die would simply be hastening her inevitable death, so that she might avoid some weeks of agony." ${ }^{14}$

The argument for allowing doctors to help patients to die in such circumstances is extremely powerful. As another American judge put it, “... what interest can the state possibly have in requiring the prolongation of a life that is all but ended? Surely the state's interest lessens as the potential for life diminishes.... And what business is it of the state to require the continuation of agony when the result is imminent and inevitable? ... The greatly reduced interest of the state in preserving life compels the answer to these questions: 'None'."15

Given the strength of the arguments in favour of legalising PAS, what are the arguments against?

\section{ETHICAL ARGUMENTS AGAINST PAS Religious arguments}

Historically laws against suicide and mercy killing have developed from religious doctrine, for example, the claim that only God has the right to determine when a person will die, or that committing suicide is a blasphemous rejection of God's gift of life. Whatever the force of such arguments for believers, these arguments do not justify restricting the liberty of individuals in a secular society.

\section{Physicians as healers}

Many physicians regard PAS as violating a fundamental tenet of medicine: to heal and not to harm. Dr Kenneth Stevens, chairman of the department of radiation oncology at the Oregon Health and Science University in Portland, and an opponent of the Oregon law, says, "I went into medicine to help people. I didn't go into medicine to give people a prescription for them to die." ${ }^{\prime 16}$ However, proponents of PAS will answer that sometimes giving people a means of ending their lives is helping them. The case against legalising PAS should not rest on the implausible assumption that death is never a benefit to the dying person. Heart rending stories, like that of Diane Pretty, make it clear that sometimes the only thing a compassionate physician can do is help his or her 
patient die quickly and painlessly. However, it is a mistake to think that if there are some cases in which PAS would be ethically justified, then it follows that the law ought to be changed. Statutes are inherently general. They do not pick out specific instances in which something is justifiable or reasonable, and allow these to be permitted. Rather, they must be drafted to cover many cases. Therefore, the issue is not whether this individual or that individual should be allowed to enlist the help of a physician in dying. The issue is rather whether it is possible to draft a statute that will cover all and only the justifiable cases.

\section{KAMISAR'S CONSEQUENTIALIST APPROACH}

This point was made by Yale Kamisar in his classic article in 1958 responding to Glanville Williams' The Sanctity of Life and the Criminal Law. Williams criticised the "sanctity of life" approach behind anti-euthanasia legislation, assuming that the only arguments against legalising euthanasia were religious ones. His mistake, Kamisar argues, is failing to consider the social consequences of legalisation. Kamisar is not an absolutist on mercy killing; he does not claim that it would be wrong in every case. In fact, he says that if he could know that a person was in fact (1) terminally ill, (2) suffering intolerable pain that (3) couldn't be relieved, and (4) had a desire to die that was (5) unwavering and (6) rational, he would "hate to have to argue that the hand of death should be stayed". ${ }^{3}$ The trouble is that it is hard to know any of these things with any degree of certainty. For example, in Oregon, "terminal disease" is defined as "an incurable and irreversible disease that has been medically confirmed and will, within reasonable medical judgment, produce death within six months". ${ }^{17}$ However, while doctors can predict death when it will occur within days, the prediction of death within six months is much less reliable. This being the case, how useful is the Oregon requirement as a guideline?

In its report on assisted suicide and euthanasia, the New York State Task Force characterised the treatment of severe pain in hospitalised patients as "regularly and systematically inadequate". The report cited a study of 897 physicians caring for cancer patients, in which $81 \%$ of respondents agreed with the statement "The most common form of narcotic abuse in the care of the dying is undertreatment of pain" ${ }^{18}$ Critics of legalisation acknowledge the problem of pain, but argue that the answer is not to legalise PAS, but to improve palliative care. The World Health Organization has endorsed palliative care as an integral component of a national health care policy and has strongly recommended to its member countries that they not consider legalising PAS and euthanasia until they have addressed the needs of their citizens for pain relief and palliative care. ${ }^{19}$

This assumes that palliative care is quite different from assisted suicide and euthanasia, an assumption that has been questioned. In Oregon, more than three quarters of the patients who have died under its Death with Dignity Act have been simultaneously enrolled in hospice programmes. ${ }^{20}$ PAD might be offered as an option within palliative care, for those for whom pain relief is not the primary issue. Diane Pretty characterises the limits of palliative care this way: "Whilst palliative care makes a great difference to many people, it is not the solution for all. Some terminal pain and other distressing symptoms cannot be fully controlled, even with the best care-I know! However, it is quality of life, and individual feelings about dignity rather than pain, that is often the main reason behind a patient's request for help in dying." ${ }^{21}$

The appeal to dignity, however, is problematic, partly because it is very vague (what is it to die with dignity?) and partly because it may seem to embody objectionable and even discriminatory attitudes toward the disabled. People sometimes appeal to dignity as impaired by dependence on machines, or by a loss of control of bodily functions-but why? Does my dependence on a word processor reduce my dignity? Does dignity reside in the bladder or bowel? ${ }^{22}$ Perhaps a better conception of human dignity would not rest on absence of physical impairments or deterioration.

\section{Each person should be able to decide for himself what death with dignity is}

Ronald Dworkin might object to the very notion of a "better" conception of dignity. The point, he might say, is that each person should be able to decide for himself what death with dignity is. If a terminally ill person prefers death to being tethered to a ventilator or to loss of bodily control, he should be able to request it without being criticised for politically incorrect attitudes regarding disability! Dworkin writes, "Making someone die in a way that others approve, but he believes a horrifying contradiction of his life, is a devastating, odious form of tyranny". ${ }^{23}$

However, even if this is accepted, the question confronting society is not whether a particular individual is justified in wanting PAS. The broader question is the impact the change in the law will have on society. Assuming that some cases warrant PAS, is it possible to write legislation that will apply only to those individuals? Or will legislation passed out of compassion sweep up some who are not really tired of life, but think others are tired of them? Kamisar writes: "In a society which recognizes by specific legislation that assisted suicide (and hence suicide as well) is a rational and reasonable course of action in certain circumstances, and a society in which assisted suicide will not only be thinkable but speakable, will it be or become the "right" thing to do under certain circumstances? The courageous thing? The disappointing or selfish or cowardly thing not to do?" case anyone thinks Kamisar's worries are unrealistic, I should point out that at least one writer has advocated a "duty to die" to avoid imposing serious financial, physical, or emotional burdens on family members. ${ }^{24}$ )

In addition to the risk that some individuals may feel pressured into choosing death, there are groups of patients who may be especially vulnerable: the disabled, those with mental illness, poor people, and minority group members. The risk that death may be too easily seen as a solution to terminal illness for members of these groups is intensified by economic pressures, when healthcare budgets are being cut. As one commentator put it: "Even if the right to assisted suicide were restricted to terminally ill people, it seems likely that some-the poor, elderly, unassertive, clinically depressed, members of disfavored minorities, or some combination of all these-would be especially vulnerable to subtle or not-so-subtle promptings to choose a quick, easy (and inexpensive) exit."25

Women might also be a vulnerable group, partly because of sexism which both devalues women and idealises women as self-sacrificing, and partly because studies have shown women to be at greater risk for inadequate pain relief and for depression. ${ }^{26}$

Until very recently, no one could do more than speculate the risks. Now, however, we have Oregon's experience as objective evidence. Have the fears of the anti-PAS crowd materialised?

\section{THE EVIDENCE FROM OREGON}

Unfortunately, a clear, unambiguous answer cannot be given. On the one hand, fears that legalising PAS might lead to overuse do not seem to have been realised. Although the number of prescriptions written for PAS and the number of 
terminally ill patients taking lethal medication has increased in Oregon since legalisation, the number has remained small compared to the total number of deaths in Oregon, with fewer than one eighth of $1 \%$ of Oregonians dying by PAS. ${ }^{27}$ Indeed, a recent article suggests that "the most surprising thing to emerge from Oregon is how rarely the law has actually been used". ${ }^{16}$ It is estimated that only one out of a hundred individuals who ask about assisted suicide carry it out in the end. This has led Dr Marcia Angell, a former editor of the New England Journal of Medicine, and a supporter of PAS, to suggest that the law is too restrictive. "I am concerned that so few people are requesting it,' she said. 'It seems to me that more would do it. The purpose of a law is to be used, not to sit there on the books." ${ }^{\prime 16}$

Nor do fears about the abuse of vulnerable groups, such as the elderly, poor, uneducated, or minorities, seem to have materialised. According to an article in The Oregonian: "When doctor-assisted suicide became legal in Oregon in late 1997, critics speculated that the patients most likely to use the new law would be depressed and socially vulnerable, with untreated pain and without access to good hospice care."

But studies indicate that this is not the population seeking PAS. They are not primarily poor, but rather middle class and educated. Moreover, younger patients are more likely to use PAS than elderly ones. During 2002, all but one had some form of health insurance. And, as in previous years, most (92\%) of the patients who used PAS in 2002 were enrolled in hospice care. Indeed, the availability of PAS may have contributed to the improvement of end-of-life care. This point was made in Oregon's Fifth Annual Report: "While it may be common for patients with a terminal illness to consider PAS, a request for PAS can be an opportunity for a medical provider to explore with patients their fears and wishes around end-of-life care, and to make patients aware of other options. Often once the provider has addressed patients' concerns, they may choose not to pursue PAS. The availability of PAS as an option in Oregon also may have spurred Oregon doctors to address other end of life care options more effectively. In one study Oregon physicians reported that, since the passage of the Death with Dignity Act in 1994, they had made efforts to improve their knowledge of the use of pain medications in the terminally-ill, to improve their recognition of psychiatric disorders such as depression, and to refer patients more frequently to hospice." ${ }^{28}$

On the other hand, opponents of PAS claim that there have been abuses, that there are insufficient safeguards, and that the existing safeguards do not work. According to Wesley $\mathrm{J}$ Smith, "Oregon's protective guidelines offer scant protection to vulnerable and depressed patients". ${ }^{29}$ He gives as examples of abuses the cases of Kate Cheney and Michael Freeland.

\section{Kate Cheney}

Kate Cheney was 85 years old when she was diagnosed with inoperable stomach cancer. Her daughter, Erika, a retired nurse, came from Arizona to Portland to care for her mother. She went with her mother to request the lethal prescription. Erika thought the doctor at Kaiser Permanente, the HMO in which her mother was enrolled, was "dismissive" of the request and requested a new one. Kate's second doctor arranged for a psychiatric evaluation, a standard procedure at Kaiser. "The psychiatrist found that Kate understood some things-including that she was incurably ill and had weeks or months to live. But she didn't remember the details of her hospital stay in May or the names of her hospice nurses or her new doctor." ${ }^{30}$ He noted that although assisted suicide seemed to be consistent with Kate's values throughout her life, "she does not seem to be explicitly pushing for this". Because the psychiatrist concluded that Kate lacked the "very high level of capacity required to weigh options about assisted suicide", her request for a prescription was denied. According to the psychiatrist, although Kate seemed to accept the assessment, Erika became angry. ${ }^{30}$

A second competency evaluation was performed, this time with a clinical psychologist who asked to meet with Kate alone. The psychologist concluded that there was no severe impairment that would limit Kate's ability to make a medical decision. She wrote that Kate's "choices may be influenced by her family's wishes and her daughter, Erika, may be somewhat coercive", but that Kate "demonstrated the capacity to weigh the differences and articulate her own values". ${ }^{30}$

Because the two evaluations drew different conclusions as to Kate's competency, her doctor and Dr Robert Richardson, director of the Kaiser Permanente Ethics Service, who oversaw Kate's case, were not ready to approve the medication. A family meeting, with Kate, Erika and her husband, and granddaughter, Pat, and her husband, was called. Pat told Kate that getting the prescription was Kate's choice. The family made it clear "they were there for her regardless". ${ }^{30}$ The next day, Kate called and arranged to see Dr Richardson alone. She told him that if she could no longer attend to her personal hygiene-she expelled waste into a bag through a tube attached to her intestine-or get out of bed, she might decide that life had become unbearable. Richardson was convinced not only of her competency but also that she was acting on her own. ${ }^{30}$

\section{Surrounded by her family, she quickly ate the bowl of applesauce into which the barbiturates were mixed, and died within an hour}

On 23 July 1999, Kate received and put in a safe place a bottle of barbiturates, two anti-nausea pills, a beta blocker, and some mouth numbing lidocaine syrup. Erika vowed not to mention the drugs until her mother did, and she continued to take care of her mother, who grew weaker. In late August, Kate went to a nursing home for a week, to give Erika a much needed break. Erika visited regularly. On 29 August, the day they brought her home, Kate said that she wanted to use "the pill". Surrounded by her family, she quickly ate the bowl of applesauce into which the barbiturates were mixed, and died within an hour.

Wesley Smith thinks that Erika, eager to get rid of her mother, pressured Kate to opt for PAS; further, that she engaged in "doctor shopping" to get a psychologist willing to say that her mother was competent. Others see the story quite differently. They see a woman who clearly wanted to avoid a painful or undignified death, and whose entire family supported her in whatever decision she made. There is evidence supporting each version, making it very difficult to determine which the correct one is. That issue aside, the case illustrates some difficult questions about the competency requirement. What level of capacity does the Oregon law require? This is pretty much left up to the physician doing the assessment. There is no requirement for a psychiatric evaluation, unless the doctor intending to write the prescription or the consultant who confirms the prognosis believes that the patient has seriously impaired judgment due to a mental disorder. In Kate Cheney's case, the first clinician looked for a "very high level of capacity" whereas the second took the test to be absence of "severe impairment". Aside from the question of what the Oregon law requires, we can ask how high the level should be. Should memory lapses disqualify a person? Should a psychological disorder, such as senility or depression? Should there be some oversight to ensure that the person meets the required level of capacity when he or she actually takes the pills? Smith clearly thinks 
there should be. He writes: “... the meager safeguards that do exist evaporate once the lethal prescription has been issued, at which point no doctor is required to ensure that the patient remains competent, no doctor is required to be at the patient's bedside when the overdose is taken, and no one is responsible to ensure that patients are capable of understanding what they are doing when they actually take the lethal dose."29

This points to another difficult philosophical issue: should the clinician assessing competence focus primarily on the individual's current mental state, and her ability to make a rational decision now? If so, then Kate Cheney, who had some cognitive deficits, might not qualify for assisted suicide. Or is the appropriate question whether or not her request for assisted suicide stems from values she has expressed and lived by over the course of an entire life time $?^{31}{ }^{32}$ It might be argued that these are more indicative of her own true self. The fact that she currently experiences minor cognitive deficiencies and memory lapses should not necessarily bar her from choosing a death most consonant with that self. Moreover, if it is lifelong values that matter, surely it is appropriate to consult her nearest and dearest-unless, of course, they are guilty of pressuring or coercing her, an issue that was alleged in the Cheney case.

\section{Michael Freeland}

Michael Freeland was diagnosed with terminal lung cancer in 2000. Shortly after his diagnosis, he contacted Physicians for Compassionate Care, an anti-suicide group, possibly confusing it with Compassion in Dying, the organisation that represented the plaintiffs in the original Oregon assisted suicide case. He seemed distraught, and told the volunteer who answered the call, Catherine Hamilton, that he saw no purpose in undergoing chemotherapy. He also said that he lived alone and that he did not want to tell his daughter about his diagnosis, because she was moving to another state to start graduate school. Cathy assured him that with good palliative care his symptoms could be addressed. "As she would have with any other suicidal individual, she told him she did not want him to kill himself and offered to help him find treatment for depression. ${ }^{\prime 33}$ In subsequent conversations he told her of his mother's suicide when he was 21 . Shortly after her death, he attempted suicide and was treated for depression in a psychiatric hospital. He made at least two other suicide attempts and developed alcoholism, but joined Alcoholics Anonymous (AA) and remained sober for over 20 years.

Cathy kept frequent contact with Mr Freeland over the next year. With her encouragement, he did undergo chemotherapy and radiation treatment, which alleviated his symptoms significantly. On the anniversary of his receiving a terminal prognosis, however, he received a prescription for lethal drugs from Dr Peter Reagan, an assisted suicide advocate associated with the Compassion in Dying Federation. According to Wesley Smith, Dr Reagan is often referred to patients when their own physicians refuse their requests for suicide drugs. "In other words, Reagan regularly takes on patients solely for the purpose of facilitating their suicides." 29

Mr Freeland's primary care doctor prescribed sertraline for his depression, which improved. However, after his ex sisterin-law began pursuing guardianship, he grew upset. "He had saved a substantial amount of money, and it was important to him to retain control of his resources. His doctor became worried that the patient was increasingly suicidal, or even homicidal, and he arranged for the patient to be placed on an involuntary hold." ${ }^{32}$ He was admitted to the hospital psychiatric ward.
In the emergency room, he was evaluated for "possible suicidal or homicidal ideation". The mental status report described his speech as clear and his thought processes as well organised. He denied thoughts of harming himself or others. "He was alert and oriented and judged to have aboveaverage intelligence ... The psychiatrist diagnosed him with depression ..., chronic adjustment disorder with depressed mood, probably intermittent delirium, narcissistic personality traits, and metastatic lung cancer with guarded prognosis." ${ }^{\prime 32}$

While Freeland was in the hospital, a social work home visit revealed that his home was uninhabitable, with piles of clutter, rodent faeces, and a lack of food and heat. Thirty two firearms and thousands of rounds of ammunition were removed by the police. The lethal medications, however, were left. A palliative care consultation ordered by the psychiatrist discussed the need for attendant care, but said that the fact that the patient had "life-ending medications" might make this problem "a moot point".

The Hamiltons note that after Freeland was discharged, the same psychiatrist wrote a letter to the court supporting guardianship, saying that Mr Freeland was unable to handle his own finances and was "susceptible to periods of confusion and impaired judgment". The Hamiltons find it perplexing "how the psychiatrist could leave the lethal drugs with his depressed patient, apparently believing he had a right to the overdose, and then could write a letter to the court only a day later, claiming the patient was not competent to make his own decisions. ${ }^{132}$ However, this is not necessarily perplexing. Competence is a "decision specific" capacity. Someone can be incompetent as regards managing his own finances but competent to make medical decisions, including decisions to forego life sustaining treatment or to choose assisted suicide. ${ }^{34}$

In the end, Freeland did not take the barbituates. He continued his contact with the Hamiltons, as well as some old friends from AA and others, who began to visit him daily. $\mathrm{He}$ dismissed hospice, decreased his pain medication and both his mood and cognitive clarity improved for several months. However, towards the end of his life, pain became a significant factor again. The pain medication he took, oxycodone, caused excruciating constipation, which led him to stop eating and drinking. He became confused and more suspicious, and wondered what might be in the pain medications, so he stopped taking them. He told the Hamiltons that he was desperate with the pain and was on the verge of killing himself with the overdose.

\section{If PAS is legalised, great care must be taken to ensure that it is not offered to individuals whose "unbearable suffering" is actually treatable depression}

The Hamiltons explained to him that he was frightened because of his confusion, but that pain medication and fluids would help him. "Cathy then insisted that his doctor should prescribe a morphine pump to be delivered the next day so his confusion would not interfere with his receiving needed pain relief. She also arranged for a 24 hour attendant care, which he could readily afford. With these interventions his confusion cleared, his pain abated, and he felt much relieved during the remaining two weeks of his life, even while his physical condition deteriorated." ${ }^{\prime 33}$ During this time, he was able to say goodbye to the many people who had helped him and to reconcile with his daughter, from whom he had been alienated during the psychiatric hospitalisation.

Once again, there are two ways to see the story. Barbara Coombs Lee, the president of the Compassion in Dying Federation, said that her group had worked with Mr Freeland extensively, and disagreed with the Hamiltons' evaluation of 
him as someone incapable of making reasoned medical decisions. "None of the physicians who were caring for him judged him incapable of making this very important health care decision, and he proved them right. He never did spontaneously, irrationally and out of some depressive pathology take his medications. He never took them at all. I would look at this case and say it shows the system works." ${ }^{\prime 35}$

The Hamiltons would undoubtedly respond that $\mathrm{Mr}$ Freeland's not taking the medications is due to their interventions, not the care provided by hospice, and certainly not the safeguards in the Oregon law. Cathy repeatedly reminded $\mathrm{Mr}$ Freeland that she did not want him to kill himself, and did whatever she could to ameliorate his suffering. This is because her organisation takes the traditional clinical approach, where suicide is always an outcome to be avoided. "The patient's life is always considered worth protecting and talk of suicide is considered a plea for help." ${ }^{\prime 32}$ A wish for death is considered symptomatic of an underlying psychiatric illness that needs to be treated-involuntarily if necessary. By contrast, on the assisted suicide competency approach, what matters is whether patients are competent to make medical decisions. The fact that patients suffer from depression does not necessarily preclude them from receiving drugs to help them end their lives. For this reason, it may not be considered terribly important to diagnose, much less treat, depression-a defect, in my view, of this approach. If PAS is legalised, surely great care must be taken to ensure that it is not offered to individuals whose "unbearable suffering" is actually treatable depression.

The Hamiltons argue that the two paradigms regarding suicide are incompatible. They suggest that doctors who begin with the competency approach often revert to the traditional approach when the patient evidences serious depression or confusion, creating an inconsistent, even incoherent, treatment plan. However, why could not the two paradigms be combined? Recognising a right to assisted suicide should not preclude first making every attempt to alleviate the symptoms that motivated the request for PAS. Indeed, the evidence from Oregon is that the new law has improved palliative care. Why, then, wasn't Mr Freeland given a prescription for lethal drugs and anti-depressant medication, home attendant care, and a morphine drip? It is disturbing that Cathy Hamilton had to fight so hard for $\mathrm{Mr}$ Freeland to get the care he needed, which suggests that in practice, if not in principle, the two approaches may conflict. Ideally, it should be possible to give people help in ending their lives when they request it, without intimating that their lives are no longer valuable.

\section{CONCLUSION}

So, where does this leave us? In 1997, when my husband David Pratt and I first wrote an article together on PAD, we recommended paying close attention to the experiments being carried out in Oregon and the Netherlands, saying, "In view of the potential for subtle and not-so-subtle pressure on vulnerable populations, a careful "go slow" approach is warranted..$^{36}$ (See also David Pratt's further work. ${ }^{37-38}$ ) Now, seven years later, it is hard to give any more specific advice. The cases of Kate Cheney and Michael Freeland are not clear cases of abuse, and even if they were, two cases in seven years is hardly evidence of widespread abuse. Opponents of Oregon's law respond that there may well be other cases. Without a "systematic and careful, independent review ... of medical and psychiatric records ... by multiple clinicians with differing viewpoints of all psychiatric records with identifying data of assisted-suicide patients masked, ... the information available will remain based on [Oregon Health Division] reports, which rely on the assisted-suicide doctors themselves, and on the records of individual patients who are willing to release their medical records independently. To date, Michael Freeland is the only person in over 250 cases of prescribed overdoses to do so." ${ }^{\prime 32}$

Thus, commentators disagree on whether the reporting from Oregon is accurate, as well as on what the figures mean. Moreover, such disagreement seems to depend on or at least mirror their basic moral and philosophical convictions. The Hamiltons distrust the reports of the so-called "assisted suicide doctors," while Scott Swenson, executive director of the Death With Dignity National Center, accuses the Hamiltons of having in the past exaggerated the facts of cases to undermine the law. "'I just have my doubts because of the source of the material,' Mr Swenson said. He added, 'If everything they said was true, we would need to take a serious look at exactly what happened and when."'35 This partisanship makes it difficult to assess the data, which is unfortunate for those of us who would like to see the question of whether PAS should be legalised turn on objective, empirical evidence about both the need for PAS and the risk of mistake and abuse. This is further complicated by the fact that it is often difficult to determine the relevance of the experience of jurisdictions that may differ in significant ways from one's own country or state. ${ }^{39}$

For all of these reasons, I remain conflicted. I am as moved as anyone by the stories of individuals like Diane Pretty, but dubious that these justify a sea change in medicine and the law. It is not clear that a change in the law was necessary to avoid Diane's tragic end. Had Diane been able to take her own life, she would have been free to do so. The case arose because she could not take a lethal dose without help. (Incidentally, this means that if Diane had been a resident of Oregon, she would not have been eligible for PAS, since Oregon law mandates that the patient herself administer the lethal dose.) For this reason, Diane sought reassurance that her husband would not face prosecution if he helped her to die. In reality, he was unlikely to be prosecuted, much less convicted; there have been very few such prosecutions and almost no convictions-unless there is evidence that the deceased was forced or pressured to die. Some may argue that it is hypocrisy to have a law that is not enforced. However, even if this is granted, an argument for legalising PAD based on avoiding hypocrisy is not as strong as one based on suffering.

I am not suggesting that the Oregon law should be repealed. The Oregon voters have decided after careful discussion and debate that the need is real, and they have attempted to minimise the risks with safeguards-perhaps too many safeguards, if Marcia Angell is right. Oregon has the right to make its own decision regarding PAS (and Attorney-General Ashcroft was rightly rebuked by the Ninth Circuit for his attempt to undermine the law). My point is rather that before the rest of us climb on the PAS bandwagon, there are many crucial issues to be hammered out. The discussion should continue. At present, the case for legalising PAS seems to me to be still-in the words of the Scottish verdict-not proven.

\section{REFERENCES}

1 The Oregon Death with Dignity Act, a citizens' initiative, was first passed by Oregon voters in November 1994, but not implemented until after a legal injunction was lifted on 27 October 1997. http://www.ohd.hr.state.or.us/ chs/pas/pas.cfm (accessed 12 January 2005).

2 Williams G. The sanctity of life and the criminal law. New York: AA Knopf, 1966.

3 Kamisar Y. Some non-religious views against proposed 'mercy-killing' legislation. Minn Law Rev 1958;42:969-1042.

4 Kamisar $Y$. Physician-assisted suicide: the problems presented by the compelling, heartwrenching case. J Crim Law Criminol 1998;88:1121-46.

5 Arras JD. Physician-assisted suicide: a tragic view. J Contemp Health Law Policy 1997; 13:361-89.

6 The SUPPORT Principal Investigators. A controlled trial to improve care for seriously ill hospitalized patients. The study to understand prognoses and 
preferences for outcomes and risks of treatments (SUPPORT). JAMA 1995;274:1591-8.

7 Colburn D. Study puts face on patients in assisted suicide. The Oregonian, 12 June 2003.

8 O'Neill O. Autonomy and trust in bioethics. Cambridge: Cambridge University Press, 2002.

9 Dworkin R. Introduction to assisted suicide: the philosophers' brief. The New York Review of Books, Vol XLIV, 1997:41-7.

10 Dworkin R, Nagel T, Nozick R, et al. The philosophers' brief. The New York Review of Books, Vol XLIV, 1997:41-7.

11 Compassion in Dying $v$ State of Washington 49 F3d 586 (1995), at 590-1.

12 Warnock M. Euthanasia: law and morality Counsel, August 2002:14-15, at 14.

13 Diane Pretty dies. BBC News, Health, 12 May 2002. http://news.bbc.co.uk/ 1/hi/health/1983457.stm (accessed 12 January 2005).

14 Baroness Warnock. "Death Where is Thy Sting?" Counsel: The Journal of the Bar of England and Wales, August 2002, 14-15, at 14.

15 Quill $v$ Vacco, 80 F3d 716 (2d Cir. 1996), at 729-30.

16 Schwartz J, Estrin J. In Oregon, choosing death over suffering. New York Times, Science Times, 1 June 2004, F4.

17 Oregon Department of Human Services. Oregon's Death with Dignity Act, http://www.dhs.state.or.us/publichealth/chs/pas/pas.cfm /accessed 12 January 2005).

18 New York State Task Force on Life and the Law. When death is sought: assisted suicide and euthanasia in the medical context. Albany, NY: May 1994:43.

19 Foley KM. Competent care for the dying instead of physician-assisted suicide. N Engl J Med 1997;336:54-8.

20 Quill TE. Dying and decision making-evolution of end-of-life options. N Engl J Med 2004;350:2029-32.

21 Voluntary Euthanasia Society (UK). http://www.justice4diane.org.uk/ safety.asp (accessed 12 January 2005)

22 Ackerman F. Assisted suicide, terminal illness, severe disability, and the double standard. In: Battin M, et al, eds. Physician-assisted suicide: expanding the debate. New York: Routledge, 1998:151.

23 Dworkin R. Life's dominion: an argument about abortion, euthanasia, and individual freedom. New York: Alfred A Knopf, 1993:217.

24 Hardwig J. Is there a duty to die? Hastings Cent Rep 1997;27:34-42.
25 Burt RA. Death made too easy. New York Times, 16 Nov 1994, A 19

26 Wolf SM. Gender, feminism, and death: physician-assisted suicide and euthanasia. In Wolf S (ed). Feminism and bioethics. New York: Oxford University Press, 1996.

27 Fifth Annual Report on Oregon's Death with Dignity Act, Comments. http:// www.dhs.state.or.us/publichealth/chs/pas/pas.cfm (accessed 12 January 2005).

28 Fifth Annual Report on Oregon's Death with Dignity Act, Patient Characteristics. http://www.dhs.state.or.us/publichealth/chs/pas/pas.cfm.

29 Smith WJ. Oregon assisted suicide abuses, the Oregon tall tale: the creepy underside of legal assisted suicide, 8 May 2004. Available at www. lifeissues. net (accessed 12 January 2005).

30 Barnett EH. A family struggle: is mom capable of choosing to die? The Oregonian, 17 October 1999:G01.

31 Dresser RS, Robertson JA. Quality of life and non-treatment decisions for incompetent patients: a critique of the orthodox approach. Law Med Health Care 1989;17:234-44.

32 Rhoden NK. The limits of legal objectivity. North Carol Law Rev 1990;68:845-65.

33 Hamilton NG, Hamilton C. Competing paradigms of responding to assistedsuicide requests in oregon: case report. Presented at the American Psychiatric Association Annual Meeting Symposium on Ethics and End-of-Life Care: New Insights and Challenges, New York City, 6 May 2004, Available at http:// www.pccef.org/articles/art28.htm.

34 Lo B. Assessing decision-making capacity. Law Med Ethics 1990; 18:193-203.

35 Schwartz J. Questions of safeguards in suicide law. New York Times, 7 May 2004:A22.

36 Pratt DA, Steinbock B. Death with dignity or unlawful killing: the ethical and legal debate over physician-assisted death. Crim Law Bull 1997;33:226-61.

37 Pratt DA. Too many physicians: physician-assisted suicide after Glucksberg/ Quill. Albany Law Journal of Science \& Technology 1999;9:161-234.

38 Pratt DA. Recent developments relating to physician-assisted suicide. NYSBA Health Law Journal 2003;8:40-7.

39 Battin MP. Euthanasia: the way we do it, the way they do it. In: Steinbock B, Arras JD, London AJ, eds. Ethical issues in modern medicine, 6th edn. McGraw-Hill, 2002:401-15.

\section{Register now!}

10th European Forum on Quality Improvement in Health Care 13-15 April 2005, ExCel Conference Centre, London For further information on how to register please go to: http://www.quality.bmipg.com 